\title{
Number of roles and well-being among older adults in the Czech Republic
}

\author{
BY BARBORA HUBATKOVÁ*
}

\begin{abstract}
This article aims to analyze the relationship between number of roles, stress, and overall well-being among 50- to 70-year-olds in the Czech Republic and to assess whether this link can be at least partially attributed to other role-related factors, namely individual role types, role overload, and role strain. Using OLS regression, the number of roles was found to be positively related to both stress and overall well-being. The link between multiple roles and well-being among elderly Czechs was mostly irreducible to other role-related factors. However, some of the positive association between number of roles and stress was likely due to occupying a worker role, experiencing role overload and experiencing one role as particularly concerning or difficult, while some of the positive association between multiple roles and overall well-being was partially attributable to occupying grandparental and "active ager" roles.
\end{abstract}

Keywords: number of roles, stress, well-being, strain, enhancement, active aging.

*Barbora Hubatková, Office for Population Studies, Faculty of Social Studies, Masaryk University, Joštova 10, Brno, Czech Republic 
International Journal of Ageing and Later Life

\section{Introduction}

Later life has often been characterized by an overall withdrawal from social roles (Adelmann 1994). Yet nowadays, many older people actually tend to occupy multiple roles - for example, due to their becoming grandparents while still fully engaged in paid work (Ochiltree 2006; Reitzes \& Mutran 2004). From the perspective of active aging, multiple role occupancy in older age should foster well-being, as embarking upon numerous activities is believed to improve quality of life (Avramov \& Mašková 2003; Uhlenberg 2005). On the contrary, a multitude of roles might also be a burden and a source of stress, especially as role accumulation may lead to role conflict and role overload (Adelmann 1994; Sieber 1974). The aim of this article is to analyze the relationship between number of roles and wellbeing among older adults using survey data collected in 2014 in the Czech Republic. This is, in part, a way to address existing gaps in our knowledge about roles in later life (e.g. Adelmann 1994). The exploratory analysis has two main aims: to examine the nature of the association between number of roles and stress, and number of roles and overall well-being in the population of older Czechs, and to assess whether this link can be at least partially attributed to other role-related factors, namely the specific types of roles a person occupies, role overload, and the experience of role-related strain. In the following part, I will first briefly overview the main theoretical hypotheses concerning the relation between multiple roles and wellbeing. Next, I will describe and analyze the data, and discuss the results.

\section{Number of roles and well-being}

In literature, two broad perspectives relating to the association between multiple role occupancy (or role accumulation) and outcomes such as well-being, stress, and health can be identified: (1) the role strain hypothesis, which predicts multiple roles to have a detrimental effect and (2) the role enhancement hypothesis, which argues in favor of a beneficial effect (summary, e.g., Adelmann 1994; Ahrens \& Ryff 2006). The term "role strain" was first used by William Goode (1960) "to signify the difficulty of performing multiple roles, asserting that the resultant tendency toward strain is a ubiquitous feature of social life" (Sieber 1974: 567). Generally, strain is assumed to be the result of either conflict between roles, role overload (Adelmann 1994: S277), or perhaps the contagion of stress between roles in one's roles 
set (Bolger et al. 1989). Role conflict refers to conflicting expectations and demands stemming from different roles (Coverman 1989; Hecht 2001; Peterson et al. 1995; Reilly 1982; Sieber 1974). Role overload is understood as the situation in which one has too much to do and not enough time (or energy) to do it ${ }^{1}$ (Coverman 1989; Hecht 2001; Pearlin 1989; Perry-Jenkins et al. 2007; Peterson et al. 1995; Sieber 1974). The perception of overload was theorized to depend upon the extent to which different roles are demanding - with people whose roles are less demanding being less likely to report role overload (Reilly 1982). Furthermore, an individual's commitment to various roles was also emphasized and Reilly (1982) warned against confusing low commitment with role overload (cf. Marks 1977).

The notion of the overall harmfulness of multiple roles (role accumulation, role strain) was contested by Sieber (1974), who argued that rewards and gratifications stemming from occupying multiple roles should outweigh any tensions brought about by role overload and role conflict. In his paper, he highlighted four groups of such rewards: (1) role privileges, (2) overall status security, (3) resources for status enhancement and role performance, and (4) personality enrichment and ego gratification. This means that multiple roles may bring benefits (rather than strain) by providing more rights and liberties to their incumbents; by providing buffers against failure or stress; by providing valuable resources, for example, in the form of social capital; and by enriching one's personality. Furthermore, role overload and even role conflict can in themselves be beneficial as they might generate the feeling of being needed. Moreover, "individuals are often esteemed solely by virtue of their possessing a wide repertoire of roles" (p. 576; cf. Nordenmark 2004).

Evidence regarding the impact of multiple roles on outcomes such as stress, well-being, and both mental and physical health has so far been mixed, but many findings lend support to the enhancement rather than the strain hypothesis (as summarized in Adelmann 1994; Ahrens \& Ryff 2006; Coverman 1989; Hecht 2001; Hong \& Seltzer 1995; Glynn et al. 2009; Nordenmark 2004). Adelmann (1994) nevertheless notes that, in many

\footnotetext{
${ }^{1}$ The concept of role overload is not a straightforward one but its definitions tend to be based around "time" and "energy." However, Marks (1977) argued that as time and energy are both social constructs rather than objective limitations, role overload functions as a socially acceptable excuse for individuals uncommitted to particular roles.
} 
International Journal of Ageing and Later Life

instances, an inadequately small number of roles was used (usually three - employee, parent, and spouse). On the contrary, well-being might be affected by the quality rather than the quantity of roles (e.g. Baruch \& Barness 1986; Nordenmark 2004), the meaning attached to roles by their holders (Simon 1995), or the particular role types present within the role set and their combinations (Hong \& Seltzer 1995). Other authors have also suggested that the subjective feeling of being overwhelmed by tasks is likely to be a better predictor of stress than the number of roles or demands per se (summary in Pearson 2008). Yet, analyses of the effect of role overload have also yielded mixed results (summary in Coverman 1989) with some studies showing a detrimental effect (Coverman 1989; Crouter et al. 2001; Higgins et al. 2010; Glynn et al. 2009), others a favorable effect (summary in Coverman 1989), and some finding no effect at all (Hecht 2001). Coverman (1989) attributed these differences in findings to the inconsistent way role overload has been conceptualized and measured across studies.

\section{Number of roles and well-being in later life}

Until relatively recently, later life was generally characterized by role loss (often irreversible) and role vagueness (Adelmann 1994; Hong \& Seltzer 1995). This was in accordance with the disengagement theory, which posited "that the gradual withdrawal from social interactions and activities is an inevitable accompaniment of old age, which eases the transition to death, thereby with minimal disruption to society when death occurs" (Bowling 2008: 293). However, improvements in longevity and health (Bengtson 2001) have changed this outlook (Bowling 2008). Nowadays, older people are more likely to combine more roles - for example, due to becoming grandparents while still fully engaged in paid labor and other personal endeavors (Ochiltree 2006; Reitzes \& Mutran 2004), or as a consequence of active aging in retirement (Avramov \& Mašková 2003; Uhlenberg 2005). More roles are also retained into higher ages (Adelmann 1994). Despite this, the link between the number of roles and well-being in later life remains largely under-researched (Adelmann 1994; Glaser et al. 2005). The concept of active aging operates upon the assumption that the combination of and partaking in multiple activities including paid work, volunteering, and active leisure enhance personal autonomy, health, and 
general quality of life and life satisfaction (Avramov \& Mašková 2003; Uhlenberg 2005). Moreover, the elderly might enjoy the feeling of being busy, useful, or needed, especially faced with some of the common negative old-age stereotypes (e.g. isolation, dependency; Dionigi 2015). Some authors also mention that role underload (i.e. having too few roles), as well as role overload, might have a detrimental impact on well-being (summary in Shultz et al. 2010). On the contrary, multiple roles (and the resulting role conflict and overload) might be felt as more strenuous in older age - for example, as personal resources such as health or mobility diminish, or as work, family or caregiver roles interfere with hobbies and other preferred activities. ${ }^{2}$ Existing evidence, despite its limitations, so far points to a positive association between number of roles and well-being in older age (Adelmann 1994; Hong \& Seltzer 1995).

In the Czech Republic, systematic research into the number and types of roles and activities in later life is mostly missing, but data that can be drawn from existing sources seem to indicate that later life is generally not characterized by role withdrawal. Paid employment is usually pursued until the statutory age of retirement by both men and women (e.g. 75\% of retirees in the 2011 wave of the Survey of Health, Ageing, and Retirement in Europe [SHARE] stated that they retired because they became eligible for a state pension); but about $37 \%$ of $60+$ respondents in the Life in Old Age survey (2002) reported that they continued working even after reaching the statutory age limit, and $15 \%$ of respondents in the same survey described themselves as "working pensioners." In respect to family, at least some roles - especially those of spouse and parent - are, by their nature, retained into high age, while others, such as the role of grandparent, are added to the role set. According to the 2011 population census, only $4 \%$ of Czechs aged 50+ have never married and only 5\% of women in the same age group have never had children (United Nations 2017). Increasing longevity also means the prolonged co-existence of several generations (Bengtson 2001). For example, among 50+ respondents in SHARE (2013), $20 \%$ had at least one parent still alive, more than $80 \%$ had at least one grandchild, and $23 \%$ had at least one great-grandchild.

${ }^{2}$ For example, in her study among Czech active aging women, Hasmanová Marhánková (2013) found that many grandmothers - while frequently engaged with their grandchildren - refused to make grandparenting superior to other activities. 
International Journal of Ageing and Later Life

Moreover, these family roles often relate to care provision: in the same survey, more than $60 \%$ of persons who had at least one parent still alive and who reported that they had provided help in the past year helped their parents or in-laws; and about half of all grandparents looked after their grandchildren. Where leisure is concerned, older Czechs seem to be mostly drawn to passive activities: for example in 2011, 80\% of SHARE respondents had read magazines and books in the past year, and $56 \%$ had done word or number games, while only $9 \%$ had attended education or training courses. However, 50+ year-olds in the European Social Survey (2014) spent on average 2.4 days a week exercising for 30 minutes or longer (compared to 2.9 days in the 15-49 age group). Moreover, about $40 \%$ of $50+$ respondents in the European Values Study (2008) belonged to at least one volunteer organization and about $25 \%$ of persons did unpaid work for such organizations (cf. Kafková 2012).

In the following analysis of 50- to 70-year-olds in the Czech Republic, I will address some of the existing gaps in our knowledge about social roles in later life by analyzing the relationship between multiple roles and well-being. I will try to improve upon the shortcomings of existing research by using a number of roles that exceed the usual count of three by ten, that is, 13 roles in total. In the second step, I will try to assess the extent to which this association can be - at least partially - explained by other role-related factors, such as role overload, the particular types of roles one occupies, and the strain felt within one's role set. In addition, I will assess whether the link between multiple roles and well-being differs by age. I will also briefly focus on the "active ager" role, analyzing whether active agers are actually burdened by multiple roles or role overload. In the analysis, two main dependent variables will be used: stress measured on an 11-point scale, and overall well-being assessed using an abbreviated version of the Philadelphia Geriatric Center Morale Scale (PGCM), which was devised by Lawton in the early 1970s (Hastrup et al. 1986). If multiple role occupancy is primarily associated with strain, we should see lower levels of well-being and higher levels of stress among persons occupying multiple roles. On the contrary, if multiple roles enhance well-being, then the situation should be reversed. It should be noted that as it stands, the analysis is based on the assumption that the number of roles affects wellbeing, rather than vice versa. However, the results presented here should be viewed with caution as they are based on cross-sectional data and 
therefore no inference about causality in the relationship can be made. This limitation will be discussed in the final part of the article.

\section{Data, Variables, Methods}

To analyze the relationship between number of roles and well-being, I will make use of data from the Life Roles survey conducted in the Czech Republic in September 2014 among persons aged 50 to 70. The general aim of this survey was to collect data on older persons' activities, retirement, involvement with children and grandchildren, care provision, and social roles. This makes it highly suitable for the analysis, especially as it contains a section focused on the number, type, and evaluation of roles occupied. The survey was conducted using the computer-assisted personal interviewing (CAPI) method, with interviews lasting 43 minutes in average. The sample was created using quota sampling: In the first step, information from the 2011 census provided by the Czech Statistical Office was used to identify the socio-demographic structure of the Czech population aged 50 to 70 with respect to gender, age, education, NUTS 3 region, and size of place of residence. A sample of at least $N=700$ observations was then designed to match this structure, and cases were assigned to individual interviewers. In total, information was collected from $N=730$ respondents, and the final sample was representative of the population in question with respect to its selected characteristics ${ }^{3}$ (Focus 2014). For the purposes of this analysis, I dropped all observations with missing values for one or more of the dependent or independent variables $(N=27 \mathrm{obs}$.). This then yielded a sample size of $N=703$ observations.

The main independent variable was the number of roles. Respondents were given a list of roles and asked to state for each individual role whether or not they occupied it. There were fourteen roles in total including such items as spouse, grandparent, worker, friend, patient, and caregiver. The variable number of roles was created by adding up "yes" responses across roles and ranged from a minimum of 1 to the maximum of 13 roles (i.e. no respondent occupied all 14 roles). As already mentioned, stress and overall well-being were the two dependent variables. Stress was a continuous

\footnotetext{
${ }^{3}$ The response rate was not reported by the agency responsible for the data collection, as it was stated that it did not affect the structure of the sample.
} 
International Journal of Ageing and Later Life

variable created using the incidence and intensity of stress reported by respondents as experienced in relation to their daily activities. It ranged from 0 to 10 where (1) represents stress of the lowest intensity while (10) represents the stress of the highest intensity. Zero then applies to persons who claimed to experience no stress at all. Well-being was measured using the sum of three items adapted from the original PGCM scale. These items assessed current feelings of verve (pep), usefulness, and happiness in comparison with an earlier point in time. ${ }^{4}$ The variable ranged from 3 to 9 with (3) as the lowest and (9) as the highest level of overall well-being.

As controls, I included several elementary demographic variables: gender was a dichotomous variable coded (1) for female and (0) for male. Age was used in a categorized form with four categories: (1) 50-54, (2) 55-59, (3) 60-64, and (4) 65-70. Education had four categories that reflect the Czech system of education: (1) elementary, (2) lower secondary, vocational, (3) upper secondary, and (4) tertiary. Health was measured on a 10-point scale where (1) means "no health issues" and (10) "serious health issues." I did not include a measure of economic activity due to its collinearity with the "worker" role. In addition, to see whether the association between independent and dependent variables can be explained by other role-related factors, I included the following variables: role type, role overload, and role evaluation. Role type was represented by a series of dummy variables simply capturing whether a person did or did not occupy a particular role. From the initial list of fourteen, I chose eight (originally ten) roles: (1) spouse, (2) parent, (3) grandparent, (4) worker, (5) friend, (6) patient, and (7) caregiver. The roles of volunteer, person learning new things, and person pursuing hobbies comprised one category: (8) active ager. I defined as active agers those who reported occupying at least one of these three roles. Role overload was an index created as the sum of responses to five items ${ }^{5}$ adapted for the questionnaire from Reilly's (1982) original

4 "Compared to last year, how much pep do you have?"; "As you get older, do you feel you are useful...?"; "How happy are you nowadays compared to when you were younger?" (less-same-more)

${ }^{5}$ (1) "I seem to have to overextend myself in order to be able to finish everything I have to do," (2) "I seem to have more commitments to fulfil than other people of my age," (3) "I just can't find the energy in me to do all the things expected of me," (4) "I need more hours in the day to do all the things which are expected of me,"

(5) "I am so busy that it results in conflicts with people around me." 
13-item battery; it ranged from 5 to 25 where (5) is the lowest and (25) is the highest perceived overload. Lastly, respondents were asked to evaluate their roles and state which one (if any) caused them concern, was the most time-consuming, and was difficult to perform. For simplification, I created three dummy variables capturing simply whether or not respondents considered one of their roles to be particularly time-consuming, concerning, or difficult $(1=$ yes, $0=$ no).

The association between number of roles, stress, and well-being was analyzed using OLS regression. In both instances, I estimated twelve models. They are described in Tables 1 (stress) and 2 (overall well-being) together with relevant statistics and results of the Wald test. The first model (M1, M7) only includes the number of roles; the second model (M2, M8) adds the elementary controls of gender, age, education, and heath. The third model (M3, M9) tests for an effect of role type by adding eight selected roles. The fourth model (M4, M10) further includes role overload. A series of follow-up models was used to see whether the relation between number of roles and stress (M5A) and well-being (M11A), or role overload and stress (M5B) and well-being (M11B) differed between age groups, and also whether partaking in active aging had differing effects across age groups (M5C, M11C). Models M5D/M11D and M5E/M11E then add the interaction between the active ager role and number of roles (D) and role overload (E) to see whether this group is actually burdened by multiple roles/role overload in respect to stress and well-being. The last set of models elaborates upon the fourth model (M4, M10) by controlling for strain experienced within the role set with respect to the dimensions of time (a role in the role set is perceived as time-consuming; M6A, M12A), concern (a role in the role set is a source of concern; M6B, M12B), and performance (a role in the role set is difficult to perform, M6C, M12C). The results from selected models are presented in Tables 3 and 4 .

\section{Results}

Table 5 summarizes the descriptive statistics. We see that $53 \%$ of respondents were female and the average age was 60 years. Most respondents attained lower secondary/vocational education $(41 \%)$, while $29 \%$ of respondents attained higher secondary education, and $13 \%$ of respondents were university educated. In respect to health, respondents were neither 
International Journal of Ageing and Later Life

Table 1. Goodness-of-fit statistics of estimated OLS regression models of the association between number of roles and stress

\begin{tabular}{|c|c|c|c|c|c|c|c|}
\hline & \multirow{2}{*}{$F$} & \multirow{2}{*}{ df. } & \multirow{2}{*}{$R^{2}$} & \multirow{2}{*}{$p$} & \multirow{2}{*}{ BIC } & \multicolumn{2}{|c|}{ Wald test } \\
\hline & & & & & & $F$ & $p$ \\
\hline $\begin{array}{l}\text { Model 1: number of } \\
\text { roles }\end{array}$ & 38.86 & 1 & 0.053 & $<0.00005$ & 3123.55 & & \\
\hline $\begin{array}{l}\text { Model 2: M1+gender, } \\
\text { age, education, health }\end{array}$ & 12.21 & 9 & 0.137 & $<0.00005$ & 3110.42 & 9.65 & $<0.001$ \\
\hline $\begin{array}{l}\text { Model 3: M2+role } \\
\text { types }\end{array}$ & 7.81 & 17 & 0.162 & $<0.00005$ & 3141.87 & 2.60 & $<0.01$ \\
\hline $\begin{array}{l}\text { Model 4: M3+role } \\
\text { overload }\end{array}$ & 12.94 & 18 & 0.254 & $<0.00005$ & 3066.92 & 84.09 & $<0.001$ \\
\hline $\begin{array}{l}\text { Model 5A: } \\
\text { M4+age*number of } \\
\text { roles }\end{array}$ & 11.11 & 21 & 0.255 & $<0.00005$ & 3085.53 & 0.34 & 0.796 \\
\hline $\begin{array}{l}\text { Model 5B: } \\
\text { M4+age*role overload }\end{array}$ & 11.22 & 21 & 0.257 & $<0.00005$ & 3083.70 & 0.93 & 0.424 \\
\hline $\begin{array}{l}\text { Model 5C: } \\
\text { M4+age*active aging }\end{array}$ & 11.18 & 21 & 0.256 & $<0.00005$ & 3084.30 & 0.74 & 0.528 \\
\hline $\begin{array}{l}\text { Model 5D: M4+active } \\
\text { ager*number of roles }\end{array}$ & 12.52 & 19 & 0.258 & $<0.00005$ & 3069.40 & 3.97 & $<0.05$ \\
\hline $\begin{array}{l}\text { Model 5E: M4+active } \\
\text { ager*role overload }\end{array}$ & 12.68 & 19 & 0.261 & $<0.00005$ & 3067.04 & 6.28 & $<0.05$ \\
\hline $\begin{array}{l}\text { Model 6A: M4+role } \\
\text { evaluation: } \\
\text { time-consuming }\end{array}$ & 12.29 & 19 & 0.255 & $<0.00005$ & 3072.68 & 0.78 & 0.379 \\
\hline $\begin{array}{l}\text { Model 6B: M4+role } \\
\text { evaluation: } \\
\text { concerning }\end{array}$ & 12.55 & 19 & 0.259 & $<0.00005$ & 3068.98 & 4.38 & $<0.05$ \\
\hline $\begin{array}{l}\text { Model 6C: M4+ role } \\
\text { evaluation: difficult }\end{array}$ & 12.79 & 19 & 0.262 & $<0.00005$ & 3065.52 & 7.77 & $<0.01$ \\
\hline
\end{tabular}

Czech Republic, $N=703$ observations. 
Table 2. Goodness-of-fit statistics of estimated OLS regression models of the association between number of roles and overall well-being

\begin{tabular}{|c|c|c|c|c|c|c|c|}
\hline & \multirow{2}{*}{$F$} & \multirow{2}{*}{ df. } & \multirow{2}{*}{$R^{2}$} & \multirow{2}{*}{$p$} & \multirow{2}{*}{$\mathrm{BIC}$} & \multicolumn{2}{|c|}{ Wald test } \\
\hline & & & & & & $F$ & $p$ \\
\hline $\begin{array}{l}\text { Model 7: number of } \\
\text { roles }\end{array}$ & 52.33 & 1 & 0.068 & $<0.00005$ & 2333.67 & & \\
\hline $\begin{array}{l}\text { Model 8: M7+gender, } \\
\text { age, education, health }\end{array}$ & 20.69 & 9 & 0.212 & $<0.00005$ & 2269.39 & 15.65 & $<0.001$ \\
\hline $\begin{array}{l}\text { Model 9: M8+role } \\
\text { types }\end{array}$ & 12.36 & 17 & 0.235 & $<0.00005$ & 2301.07 & 2.57 & $<0.01$ \\
\hline $\begin{array}{l}\text { Model 10: M9+role } \\
\text { overload }\end{array}$ & 11.87 & 18 & 0.238 & $<0.00005$ & 2304.63 & 2.92 & 0.088 \\
\hline $\begin{array}{l}\text { Model 11A: } \\
\text { M10+age*number of } \\
\text { roles }\end{array}$ & 10.22 & 21 & 0.240 & $<0.00005$ & 2322.79 & 0.49 & 0.692 \\
\hline $\begin{array}{l}\text { Model 11B: } \\
\text { M10+age*role overload }\end{array}$ & 10.20 & 21 & 0.239 & $<0.00005$ & 2323.13 & 0.38 & 0.771 \\
\hline $\begin{array}{l}\text { Model 11C: M10+age*- } \\
\text { active aging }\end{array}$ & 10.15 & 21 & 0.238 & $<0.00005$ & 2324.00 & 0.10 & 0.962 \\
\hline $\begin{array}{l}\text { Model 11D: M10+active } \\
\text { ager*number of roles }\end{array}$ & 11.24 & 19 & 0.238 & $<0.00005$ & 2311.05 & 0.13 & 0.716 \\
\hline $\begin{array}{l}\text { Model 11E: M10+ active } \\
\text { ager*role overload }\end{array}$ & 11.34 & 19 & 0.240 & $<0.00005$ & 2309.54 & 1.60 & 0.207 \\
\hline $\begin{array}{l}\text { Model 12A: } \\
\text { M10+role evaluation: } \\
\text { time-consuming }\end{array}$ & 11.45 & 19 & 0.242 & $<0.00005$ & 2307.96 & 3.14 & 0.077 \\
\hline $\begin{array}{l}\text { Model 12B: M10+role } \\
\text { evaluation: concerning }\end{array}$ & 11.28 & 19 & 0.239 & $<0.00005$ & 2310.41 & 0.75 & 0.387 \\
\hline $\begin{array}{l}\text { Model 12C: M10+role } \\
\text { evaluation: difficult }\end{array}$ & 11.35 & 19 & 0.240 & $<0.00005$ & 2309.37 & 1.76 & 0.185 \\
\hline
\end{tabular}

Czech Republic, $N=703$ observations. 
International Journal of Ageing and Later Life

Table 3. Estimated coefficients from selected OLS regression models of the association between number of roles and stress

\begin{tabular}{|c|c|c|c|c|c|c|c|}
\hline & M1 & M2 & M3 & M4 & M5D & M5E & M6C \\
\hline Number of roles & $0.234^{* * *}$ & * $0.198 * * *$ & $0.159^{*}$ & $0.142^{*}$ & $0.284^{* *}$ & $0.144^{*}$ & $0.122^{\dagger}$ \\
\hline Female & & 0.094 & 0.055 & 0.106 & 0.093 & 0.093 & 0.114 \\
\hline \multicolumn{8}{|l|}{$\begin{array}{l}\text { Age ( } 50-54 \\
\text { is ref. category) }\end{array}$} \\
\hline $55-59$ & & $-0.697^{* * *}$ & $-0.713^{* *}$ & $-0.582^{* *}$ & $-0.581^{* *}$ & $-0.587^{* *}$ & $-0.589 * *$ \\
\hline $60-64$ & & $-0.831^{* * *}$ & $-0.602^{*}$ & -0.309 & -0.293 & -0.303 & -0.343 \\
\hline $65-70$ & & $-1.437^{* * *}$ & $-1.046^{* *}$ & $-0.737^{*}$ & $-0.739 *$ & $-0.739 *$ & $-0.763^{* *}$ \\
\hline \multicolumn{8}{|l|}{$\begin{array}{l}\text { Education (primary } \\
\text { is ref. category) }\end{array}$} \\
\hline Lower secondary & & 0.185 & 0.171 & 0.096 & 0.071 & 0.075 & 0.102 \\
\hline Upper secondary & & 0.395 & 0.368 & 0.215 & 0.196 & 0.188 & 0.203 \\
\hline Tertiary & & 0.356 & 0.244 & 0.121 & 0.127 & 0.116 & 0.133 \\
\hline Health & & $0.254^{* * *}$ & $0.268^{* * *}$ & $0.188^{* * *}$ & $0.193 * * *$ & $0.194^{* * *}$ & $0.176^{* * *}$ \\
\hline \multicolumn{8}{|l|}{ Role type } \\
\hline Spouse & & & $-0.462^{*}$ & $-0.486^{*}$ & $-0.534^{*}$ & $-0.501^{*}$ & $-0.438^{*}$ \\
\hline Parent & & & 0.383 & $0.527^{\dagger}$ & 0.459 & $0.524^{\dagger}$ & $0.523^{\dagger}$ \\
\hline Grandparent & & & -0.089 & -0.309 & -0.325 & -0.326 & -0.245 \\
\hline Worker & & & $0.683^{* *}$ & $0.400^{\dagger}$ & $0.376^{\dagger}$ & $0.441^{*}$ & $0.392^{\dagger}$ \\
\hline Friend & & & 0.375 & 0.293 & 0.253 & 0.263 & 0.268 \\
\hline Patient & & & 0.045 & 0.029 & 0.019 & 0.044 & -0.010 \\
\hline Caregiver & & & $0.382^{\dagger}$ & 0.123 & 0.127 & 0.130 & 0.124 \\
\hline Active ager & & & -0.014 & -0.005 & $1.089^{\dagger}$ & $1.396^{*}$ & 0.001 \\
\hline Role overload & & & & $0.179^{* * *}$ & $0.178^{* * *}$ & $0.247^{* * *}$ & $0.163 * * *$ \\
\hline \multicolumn{8}{|l|}{ Interactions } \\
\hline $\begin{array}{l}\text { Active*number of } \\
\text { roles }\end{array}$ & & & & & $-0.179^{*}$ & & \\
\hline Active* overload & & & & & & $-0.099^{*}$ & \\
\hline \multicolumn{8}{|l|}{ Role evaluation } \\
\hline Difficult & & & & & & & 0.460 ** \\
\hline Intercept & $2.365^{* * *}$ & $1.751^{* * *}$ & $1.074^{*}$ & -0.754 & $-1.391^{*}$ & $-1.708^{* *}$ & -0.555 \\
\hline
\end{tabular}


Number of roles and well-being in the Czech Republic

Table 4. Estimated coefficients from selected OLS regression models of the association between number of roles and overall well-being

\begin{tabular}{|c|c|c|c|c|c|}
\hline & M7 & M8 & M9 & M10 & M12A \\
\hline Number of roles & $0.155^{* *}$ & $0.115^{\star *}$ & $0.094^{*}$ & $0.096^{*}$ & $0.098^{*}$ \\
\hline Female & & 0.034 & 0.086 & 0.080 & 0.073 \\
\hline \multicolumn{6}{|c|}{ Age (50-54 is ref. category) } \\
\hline $55-59$ & & 0.022 & 0.036 & 0.021 & 0.020 \\
\hline $60-64$ & & -0.014 & 0.026 & -0.006 & -0.019 \\
\hline $65-70$ & & -0.151 & -0.127 & -0.160 & -0.158 \\
\hline \multicolumn{6}{|c|}{$\begin{array}{l}\text { Education } \\
\text { (primary is ref. category) }\end{array}$} \\
\hline Lower secondary & & 0.156 & 0.125 & 0.133 & 0.146 \\
\hline Upper secondary & & 0.110 & 0.071 & 0.088 & 0.094 \\
\hline Tertiary & & $0.292^{\dagger}$ & 0.258 & 0.272 & 0.271 \\
\hline Health & & $-0.226^{* *}$ & $-0.194^{* *}$ & $-0.185^{* *}$ & $-0.183^{* *}$ \\
\hline \multicolumn{6}{|l|}{ Role type } \\
\hline Spouse & & & 0.145 & 0.147 & 0.111 \\
\hline Parent & & & -0.249 & -0.265 & -0.266 \\
\hline Grandparent & & & $0.236^{*}$ & $0.260^{*}$ & $0.242^{*}$ \\
\hline Worker & & & 0.116 & 0.147 & 0.114 \\
\hline Friend & & & -0.230 & -0.221 & -0.219 \\
\hline Patient & & & -0.175 & -0.173 & -0.182 \\
\hline Caregiver & & & -0.129 & -0.101 & -0.109 \\
\hline Active ager & & & $0.283^{*}$ & $0.282^{*}$ & $0.257^{*}$ \\
\hline Role overload & & & & $-0.019^{\dagger}$ & $-0.022^{\dagger}$ \\
\hline \multicolumn{6}{|l|}{ Role evaluation } \\
\hline Time-consuming & & & & & $0.311^{\dagger}$ \\
\hline Intercept & $4.570^{* *}$ & $5.896^{* *}$ & $5.905^{* *}$ & $6.103^{* *}$ & $5.896^{* *}$ \\
\hline
\end{tabular}

${ }^{* *} p<0.001 ;{ }^{*} p<0.05 ;{ }^{\dagger} p<0.1$.

Czech Republic, $N=703$ observations. 
International Journal of Ageing and Later Life

Table 5. Descriptive statistics

\begin{tabular}{|c|c|c|c|}
\hline Gender (\% of women) & 53 & Role (\% occupies) & \\
\hline Age (average) & 59.5 & Spouse & 69 \\
\hline Age (categorized, \%) & & Parent & 89 \\
\hline $50-54$ & 24 & Grandparent & 61 \\
\hline $55-59$ & 26 & Worker & 55 \\
\hline $60-64$ & 27 & Friend & 90 \\
\hline $65-70$ & 23 & Patient & 41 \\
\hline Education & & Caregiver & 25 \\
\hline Primary & 17 & Active ager & 66 \\
\hline Lower secondary & 41 & Age group 50-54 & \\
\hline Upper secondary & 29 & Spouse & 75 \\
\hline Tertiary & 13 & Parent & 87 \\
\hline Health (average) & 5.2 & Grandparent & 37 \\
\hline $\begin{array}{l}\text { Number of roles } \\
\text { (average) }\end{array}$ & 7.1 & Worker & 87 \\
\hline $\begin{array}{l}\text { Number of roles by age } \\
\text { (average) }\end{array}$ & & Friend & 88 \\
\hline $50-54$ & 7.7 & Patient & 28 \\
\hline $55-59$ & 7.6 & Caregiver & 25 \\
\hline $60-64$ & 6.9 & Active ager & 76 \\
\hline $65-70$ & 6.2 & Age group 65-70 & \\
\hline Role overload (average) & 14.3 & Spouse & 56 \\
\hline Stress (average) & 4.0 & Parent & 89 \\
\hline Stress by age (average) & & Grandparent & 85 \\
\hline $50-54$ & 4.8 & Worker & 11 \\
\hline $55-59$ & 4.1 & Friend & 87 \\
\hline $60-64$ & 3.9 & Patient & 58 \\
\hline $65-70$ & 3.3 & Caregiver & 20 \\
\hline Well-being (average) & 5.7 & Active ager & 58 \\
\hline \multicolumn{4}{|l|}{ Any role is (\% yes) } \\
\hline Time-consuming & 92 & & \\
\hline Concerning & 80 & & \\
\hline Difficult to perform & 44 & & \\
\hline
\end{tabular}


perfectly healthy nor severely ill; the average score was 5.2. On average, respondents occupied 7 roles, and while there were differences between age groups, these were not particularly stark: as we can see, the youngest persons in the sample (aged 50-54) occupied an average of about 7.7 roles, while the oldest respondents (aged 65-70) reported an average of 6.2 roles. This relatively small (but statistically significant) difference of 1.5 roles likely reflects the narrow age composition of the sample. However, it might also imply "trade-offs" between roles with aging, that is, while some roles (such as worker or offspring) are lost, others (such as grandparent or patient) are gained, which slows the pace at which role sets diminish over time. The average role overload score was 14.3 points, average stress was 4.0 (and declined across age groups), and the average overall well-being score was 5.7. The correlation between role overload and number of roles was statistically significant and positive, but weak $(0.22$ on $p<0.001)$, as was the correlation between number of roles and stress $(0.29$ on $p<0.001)$. However, there was a moderately strong positive correlation between role overload and stress (0.42 on $p<0.001$; correlations not shown).

Moving to the second part of Table 5, parent and friend were the prime roles (with about $90 \%$ of respondents occupying them), followed by spouse $(69 \%)$, active ager $(66 \%)$, grandparent $(61 \%)$, and worker $(55 \%)$. In the youngest age group (50-54), the parental, friend, and worker roles were the most frequently occupied (by about $88 \%$ of respondents), while in the oldest group (65-70), parent, friend, and grandparent were the most frequent. At least one of the "active aging" roles was reported by $76 \%$ of 50 - to 54 -year-olds and $58 \%$ of the $65+$ year-olds. The bottom part of Table 5 summarizes role strain: almost all respondents had a role in their role set that they deemed particularly time-consuming, and $80 \%$ of them occupied a role that was a source of concern. On the contrary, $44 \%$ of respondents had a role that they found difficult to perform, while $56 \%$ declared themselves to have no such role.

\section{Number of roles and stress}

Table 3 summarizes the results from selected OLS regression models of the association between the number of roles and stress. Model 1 shows that these two variables were positively related and that the estimated coefficient was statistically significant $(0.234$ on $p<0.001)$, indicating that stress 
International Journal of Ageing and Later Life

levels were higher among persons occupying multiple roles. Note, however, that in itself the number of roles accounted for only about $5 \%$ of the variance of the dependent variable. After the addition of elementary controls into Model 2, the estimated coefficient for the number of roles shrank but remained statistically significant (on $p<0.001$ ). Inspecting Model 2, we can see that stress was not affected by gender or education but declined across age groups and increased with deteriorating health. Moving to Model 3, adding role types further weakened the observed association (the coefficient changed from 0.198 in M2 to 0.159 in M3) but it remained statistically significant. In respect to individual roles, spouses were on average less stressed by their daily activities than persons who did not have a (marital) partner. On the contrary, everything else being equal, workers reported higher levels of stress on average when compared to their counterparts who did not work. Caregivers were also somewhat more stressed than persons who did not provide care, but the effect bordered on statistical significance $(p<0.1)$. Active agers were no different with regard to their stress levels than those who did not partake in volunteering, learning, or hobbies. The results from Model 4 show that role overload could not fully account for the positive association between number of roles and stress, as there was some change to the estimated regression coefficient but no change to its statistical significance. However, the perceived overload seemed to account for some of the effect of age. The effect of overload itself was positive and statistically significant: with each unit increase in overload, stress increased by 0.179 points.

Models $5 \mathrm{~A}$ to $5 \mathrm{C}$ do not lend support to the expectation that the relationship between number of roles and stress (M5A), role overload and stress (M5B), and active aging and stress (M5C) would differ across age groups. On the contrary, interactions between active aging and number of roles (M5D) and role overload (M5E) were statistically significant. The results are summarized in Table 3. Interestingly, controlling for these interactions changed the coefficient for the active ager role from negligibly negative and non-significant (in Models 3 and 4) to positive and statistically significant (on $p<0.1$ and $p<0.05$ in models M5D and M5E, respectively). This means that active agers were, on average, more stressed than their non-active counterparts (scoring more than 1 point higher on the stress scale). However, the observed interactions were negative in both models, implying that each additional role - and each unit increase 
in overload - actually decreased stress in active agers. The last series of models test for the effect of role strain. The Wald test results support the inclusion of "concern" and "difficulty." Overall, persons who saw one of their roles as a source of (non-time-based) strain scored higher on stress than their counterparts who did not. Moreover, the inclusion of these "strain" variables brought to both Models 6B and 6C a change in the statistical significance of the coefficient for number of roles from the $p<0.05$ level to $p<0.1$. Table 3 shows the results from Model 6C as the effect of "difficulty" was very slightly more pronounced than the effect of concern.

\section{Number of roles and overall well-being}

The same set of models was re-estimated with the PGCM index as the dependent variable. Model comparisons are shown in Table 2; results from selected models are shown in Table 4 . Interestingly, we see that number of roles and overall well-being were also positively related, meaning that persons occupying multiple roles - compared to their counterparts occupying few roles - were more stressed but at the same time better off in respect to well-being. The estimated regression coefficient for number of roles did shrink when controlling for demographic characteristics in Model 8, but there was no change in its statistical significance $(p<0.001)$. Among these controls, only health exerted a statistically significant negative effect (meaning there was lower well-being among persons in poorer health). The addition of role types into Model 9 further weakened the coefficient for number of roles (from 0.115 in M8 to 0.094 to M9) but again it remained positive and statistically significant. In respect to individual roles, everything else being equal, grandparents reported higher well-being on average than persons who did not identify themselves as grandparents. Moreover, active agers also scored higher on well-being than their non-active counterparts. The effect of other roles was not statistically different from zero. Adding role overload into Model 10 did not change the effect of number of roles and, based on the Wald test, was only a marginally significant improvement on Model 9 (indeed, the effect of overload on well-being was minute and significant at $p<0.1$ ). Again, interactions between age group and number of roles, role overload, and active aging did not improve Model 10, but neither did the interaction between active 
International Journal of Ageing and Later Life

aging and number of roles (M11D) and role overload (M11E), meaning that among active agers - unlike stress - there was no difference in overall well-being by number of roles occupied or the feeling of overload. The strain felt within one's role set did not constitute a particular improvement to Model 10, although occupancy of a time-consuming role (M12A) had a marginally significant $(p<0.1)$ positive effect: those who claimed to occupy such a role were better off in respect to their well-being than those who reported having no such role, everything else being equal.

\section{Discussion}

In the Czech context, I found that the number of roles was positively related to both stress and overall well-being as measured by the PGCM scale. This means that among 50- to 70-year-old Czechs, those with a higher number of roles had on average higher levels of stress but also higher levels of well-being than those with fewer roles, even when controlling for a number of other variables. As such, these findings are not fully in line with either of the above discussed hypotheses: while the strain hypothesis is supported in respect to stress, the enhancement hypothesis is supported in respect to well-being. This is curious as it would indicate that stress and well-being are not strongly linked and imply that partaking in a number of diverse activities - while simultaneously stressful - makes individuals feel useful, full of verve, and, by extension, happy, which are the items that comprise the measure of well-being used here (cf. Sieber 1974). ${ }^{6}$ While such an assertion seems feasible, the explanation might in fact lie in the nature of the dependent variables used in the analysis - especially stress specified as "experienced in relation to daily activities" might have been both too vague and too narrow to capture any effect of multiple roles that would transcend the short-lived tensions experienced in everyday life. This means that if measured differently, the results might have been less ambiguous. Anyhow, it might be useful to use both "positive" and "negative" measures of wellbeing when testing the strain and enhancement hypotheses in the future.

The positive association between number of roles and stress could not be fully explained by the types of roles a person occupied, role overload,

${ }^{6}$ Indeed, the correlation between stress and the PGCM index was extremely weak $(-0.111, p<0.01)$ in this particular dataset. 
or the strain felt within one's role set, although all three had some effect on its strength. Overall, some of the association was attributable to occupying a worker role (as seen, workers were on average more stressed than persons who did not work), experiencing role overload, and experiencing one role as particularly concerning or difficult to perform, with the effect of strain likely the decisive one (as seen, controlling for strain not only weakened the association between number of roles and stress but also changed the statistical significance of the coefficient for number of roles toward $p<0.1)$. Similarly, the observed relationship between number of roles and overall well-being could not be fully explained by other role-related factors, but seemed to be partially attributable to the types of roles a person occupied, especially if these were the roles of grandparent and active ager, that is, roles that could be understood as enjoyable (in fact, $40 \%$ of respondents in the Life Roles survey stated that the role of grandparent made them the happiest, while $13 \%$ of respondents said it was their active ager role that made them the most happy $y^{7}$. On the contrary, the effect of role overload on this association was negligible (as indeed was its effect on well-being) and so was the effect of time-based strain. Interestingly, persons who reported having a role that they deemed particularly timeconsuming had higher overall well-being than those who declared having no such role. Being busy, it would seem, elicits personal benefit rather than strain. All in all, these results indicate that the relationship between multiple roles and well-being is mostly irreducible to role type, role overload, and role strain (at least among Czechs aged 50 to 70 years).

In respect to aging, I was not able to document that the association between number of roles and well-being differed across age groups. This is also true for role overload; while overload clearly accounted for some of the effect of age on stress ${ }^{8}$ (as seen in Model 4 in Table 3), its effect was not modified by age. On the contrary, the relationship between number of roles and stress (and indeed role overload and stress) varied between

\footnotetext{
${ }_{7}$ Followed by $12 \%$ citing their parental role, $10 \%$ citing their spousal role, and $8 \%$ citing their friend role.

${ }^{8}$ In the sense that older persons were not as stressed as they experienced lower levels of overload. This is supported on the descriptive level - while 50- to 54-yearolds reported an average overload of $15.4,65+$ year-olds reported an average overload of 13.3 .
} 
International Journal of Ageing and Later Life

those who did and did not partake in active aging. We saw that when controlling for interactions between active aging and number of roles and between active aging and role overload, active agers were actually more stressed than their counterparts who did not pursue volunteering, learning, or hobbies, yet were less so with each additional role they occupied. Therefore, active agers were likely not burdened by multiple roles (either by number or by overload); the opposite was the case. We can speculate that active aging mitigates stress only where it entails/is accompanied by multiple activities rather than only a handful ("keeping busy"). However, the advantage might be down to occupying other key roles - for example, being involved in paid employment, thus generating financial resources needed to promote participation in enjoyable endeavors. Alternatively (as the direction of the relationship is unclear), lower stress levels might allow active agers to pursue multiple roles. Interestingly, this was not observed for overall well-being. While active agers scored higher on well-being, there was no benefit or burden associated with multiple role occupancy.

Several limitations of the analysis should be discussed. The definition of an "active ager" was far from exhaustive, as it was reduced to volunteering, pursuing hobbies, and learning new things. This was a practical solution; in theory, most roles occupied in older age might be considered to play a part in active aging, yet I chose to test separately for the effect of as many roles as possible. It follows that when talking about active agers, the analysis refers to those partaking in at least one out of three possible activities that have close ties to leisure. It is also true that the analysis largely omitted the gender aspect despite the fact that some previous findings pointed out that women rather than men tend to be more overwhelmed and overloaded by tasks (Simon 1995). We saw that gender had no effect on well-being, but attention was not given to the interaction between number of roles and gender, as this was beyond the scope of this article. Also, the age composition of the sample did not allow any investigation into the link between roles and well-being among persons above the age of 70 .

Most importantly, however, the cross-sectional nature of the data did not allow the direction of the relationship between number of roles and well-being to be inferred. While both the enhancement and strain 
hypotheses expect that multiple roles have an effect on well-being, wellbeing might in fact have an impact on the number of roles occupied: while persons scoring high on well-being might be more inclined to engage in multiple roles, those low on well-being might avoid role accumulation ${ }^{9}$ (cf. Adelmann 1994; Ahrens \& Ryff 2006; Hong \& Seltzer 1995; Moen et al. 1992). However, existing longitudinal evidence seems to lend support to the expectation that well-being is affected by the number of roles. For example, on the basis of their analysis of number of roles and depression among older Wisconsin mothers caring for a handicapped child, Hong and Seltzer (1995) concluded that "multiple roles preceded depression in casual ordering" (p. 939), as the change in the number of roles affected depression even with the initial depression level controlled for. A similar conclusion in respect to causality was reached by Nordenmark (2004), who analyzed number of roles and well-being in the general population of Sweden. Moreover, in an overview of analyses focused on the link between activity and well-being in later life, Adams et al. (2011) summarized that in longitudinal studies, activity often predicted well-being rather than vice versa. This being said, the accumulation of roles and the level of well-being may both be affected by other factors (such as specific personality traits) that were not accounted for by the models presented here. The results should therefore be taken with caution. Future analyses should improve upon at least some of these shortcomings, as well as introduce different measures of well-being and focus on cross-country comparison, if possible using large-scale harmonized international datasets, preferably with a longitudinal element in order to see whether multiple role occupancy in fact enhances or harms well-being in later life.

\section{Acknowledgements}

This work was supported by the Czech Science Foundation (grant number GA13-34958S)

\footnotetext{
${ }^{9}$ However, in the present analysis this cannot be said for stress, as those occupying multiple roles were more stressed - unless particularly stressed individuals seek to alleviate stress by engaging in additional roles.
} 
International Journal of Ageing and Later Life

\section{Corresponding Author}

Barbora Hubatková, Office for Population Studies, Faculty of Social Studies, Masaryk University, Joštova 10, 60200 Brno, Czech Republic. Email: 220208@mail.muni.cz

\section{References}

Adams, K. B., Leibbrandt, S. \& Moon, H. (2011). A critical review of the literature on social and leisure activity and wellbeing in later life. Ageing and Society 31(4): 683-712.

Adelmann, P. K. (1994). Multiple roles and psychological well-being in a national sample of older adults. Journal of Gerontology 49(6): S277-S285.

Ahrens, C. J. C. \& Ryff, C. D. (2006). Multiple roles and well-being: Sociodemographic and psychological moderators. Sex Roles 55(11-12): 801-815.

Avramov, D. \& Mašková, M. (2003). Active Ageing in Europe. Strasbourg: Council of Europe Publishing.

Baruch, G. K. \& Barnett, R. C. (1986). Role quality, multiple role involvement, and psychological well-being in midlife women. Journal of Personality and Social Psychology 51(3): 578-585.

Bengtson, V. L. (2001). Beyond the nuclear family: The increasing importance of multigenerational bonds. Journal of Marriage and Family 63(1): 1-16.

Börsch-Supan, A. (2017). Survey of Health, Ageing and Retirement in Europe (SHARE) Wave 4. Release version: 6.0.0. SHARE-ERIC. Data set. doi: 10.6103/SHARE.w4.600

Börsch-Supan, A. (2017). Survey of Health, Ageing and Retirement in Europe (SHARE) Wave 5. Release version: 6.0.0. SHARE-ERIC. Data set. doi: 10.6103/SHARE.w5.600

Bolger, N., DeLongis, A., Kessler, R. C. \& Wethington, E. (1989). The contagion of stress across multiple roles. Journal of Marriage and Family 51(1): 175-183.

Bowling, A. (2008). Enhancing later life: How older people perceive active ageing? Aging and Mental Health 12(3): 293-301.

Coverman, S. (1989). Role overload, role conflict, and stress: Addressing consequences of multiple role demands. Social Forces 67(4): 965-982. 
Crouter, A. C., Bumpus, M. F., Head, M. R. \& McHale, S. (2001). Implications of overwork and overload for the quality of men's family relationships. Journal of Marriage and Family 63: 404-416.

Dionigi, R. A. (2015). Stereotypes of aging: Their effects on the health of older adults. Journal of Geriatrics Article ID 954027.

European Social Survey Round 7 Data (2014). Data file edition 2.1. NSD Norwegian Centre for Research Data, Norway - Data Archive and distributor of ESS data for ESS ERIC.

European Values Study 2008: Czech Republic (EVS 2008). GESIS Data Archive, Cologne. ZA4770 Data file Version 1.1.0, doi: 10.4232/1.10165

Focus. (2014). Technická zpráva ze sbèru dat - výzkum na téma "Přetízená role" [Technical Report - "Life Roles" Survey]. Brno: Focus.

Glaser, K., Evandrou, M. \& Tomassini, C. (2005). The health consequences of multiple roles at older ages in the UK. Health \& Social Care in the Community 13(5): 470-477.

Glynn, K., Maclean, H., Forte, T. \& Cohen, M. (2009). The association between role overload and women's mental health. Journal of Women's Health 18(2): 217-223.

Goode, W. J. (1960). A theory of role strain. American Sociological Review 25: 483-496.

Hasmanová Marhánková, J. (2013). Aktivita jako projekt: diskurz aktivního stárnutí a jeho odezvy v životech českých seniorũ a seniorek [Activity as a Project. The Discourse of Active Ageing and Its Place in Lives of the Czech Elderly]. Praha: SLON.

Hastrup, J. L., Baker, J. G., Kraemer, D. L. \& Bornstein, R. F. (1986). Crying and depression among older adults. The Gerontologist 16(1): 91-96.

Hecht, L. M. (2001). Role conflict and role overload: Different concepts, different consequences. Sociological Inquiry 71(1): 111-121.

Higgins, C. A., Duxbury, L. E. \& Lyons, S. T. (2010). Coping with overload and stress: Men and women in dual-earner families. Journal of Marriage and Family 72: 847-859.

Hong, J. \& Seltzer, M. M. (1995). The psychological consequences of multiple roles: The nonnormative case. Journal of Health and Social Behavior 36(4): 386-398.

Kafková, M. P. 2012. Dobrovolnictví seniorů jako součást aktivního stárnutí [Volunteering of older people as an integral part of active ageing]. Sociológia-Slovak Sociological Review 44(2): 212-232. 
International Journal of Ageing and Later Life

Marks, S. R. (1977). Multiple roles and role strain: Some notes on human energy, time and commitment. American Sociological Review 42(6): 921-936.

Moen, P., Dempster-McClain, D. \& Williams, R. M., Jr. (1992). Successful aging: A life-course perspective on women's multiple roles and health. American Journal of Sociology 97(6): 1612-1638.

Nordenmark, M. (2004). Multiple social roles and well-being: A longitudinal test of the role stress theory and the role expansion theory. Acta Sociologica 47(2): 115-126.

Ochiltree, G. (2006). Grandparents, Grandchildren, and the Generation in Between. Camberwell, Victoria: ACER Press.

Pearlin, L. I. (1989). The sociological study of stress. Journal of Health and Social Behavior 30(3): 241-256.

Pearson, Q. M. (2008). Role overload, job satisfaction, leisure satisfaction, and psychological health among employed women. Journal of Counseling and Development 86(1): 57-63.

Perry-Jenkins, M., Goldberg, A. E., Pierce, C. P. \& Sayer, A. G. (2007). Shift work, role overload, and the transition to parenthood. Journal of Marriage and Family 69: 123-138.

Peterson, M. F., Smith, P. B., Akande, A., Ayestaran, S., Bochner, S., Callan, V., Cho, N. G., Jesuino, J. C., D’ Amorim, M., Francois, P.-H., Hofmann, K., Koopman, P. L., Leung, K., Lim, T. K., Mortazavi, S., Munene, J., Radford, M., Ropo, A., Savage, G., Setiadi, B., Sinha, T. N., Sorenson, R. \& Viedge, C. (1995). Role conflict, ambiguity, and overload: A 21-nation study. Academy of Management Journal 38(2): 429-452.

Reilly, M. D. (1982). Working wives and convenience consumption. Journal of Consumer Research 8(4): 407-418.

Reitzes, D. C. \& Mutran, E. J. (2004). Grandparenthood: Factors influencing frequency of grandparent-grandchildren contact and grandparent role satisfaction. Journal of Gerontology 59B(1): S9-S16.

Research Institute For Labour And Social Affairs. Life in Old Age 2002 (data file), version 1.0. Prague: Czech Social Science Data Archive, 2007. doi: $10.14473 /$ VUPSV00006

Shultz, K. S., Wang, M. \& Olson, D. A. (2010). Role overload and underload. Stress and Health 26: 99-111. 
Sieber, S. D. (1974). Toward a theory of role accumulation. American Sociological Review 39(4): 567-578.

Simon, R. W. (1995). Gender, multiple roles, role meaning, and mental health. Journal of Health and Social Behavior 36(2): 182-194.

Uhlenberg, P. (2005). Historical forces shaping grandparent-grandchild relationships: Demography and beyond. In M. Silverstein (ed.), Intergenerational Relations Across Time and Place (pp. 77-97). New York: Springer Publishing Company.

United Nations. (2017). Demographic Yearbook. Population Censuses' Datasets (1995-Present): Population by marital status, age, sex and urban/rural residence; Female population by age, number of children ever born alive and urban/rural residence. Available on https:/ / unstats.un.org/unsd/demographic/products/dyb/dybcensusdata. htm (Accessed: March 27, 2017) 
